\title{
تنفيذ التفتيش كإجراء جنائي في العمل الأمني وفق التشريع الكويتي
}

\author{
عبدالله عجلان عبدالله الدوسري \\ أستاذ مساعد- قسم المقررات الشرطية \\ أكاديمية سعدالعبدالله للعلوم الأمنية- الكويت \\ boajlan2011@gmail.com
}

قبول البحث: 2021/4/23

مراجعة البحث: 2021/2/27

استلام البحث: 2/3/ 2021

DOI: https://doi.org/10.31559/LCJS2021.2.1.4 
www.refaad.com
المجلة الدولية للدراسات القانونية والفقهية المقارنة

International Journal of Legal and Comparative Jurisprudence Studies (LCJS)

Journal Homepage: https://www.refaad.com/views/LCJS/Home.aspx

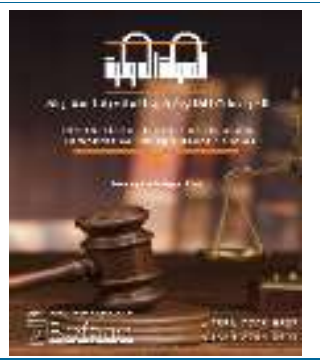

تنفيذ التفتيش كإجراء جنائي في العمل الأمني وفق التشريع الكويتي

\author{
عبد الله عجلان عبدالله الدوسري \\ أستاذ مساعد- قسم المقررات الشرطية- أكاديمية سعدالعبدالهالهه للعلوم الأمنية- الكويت \\ boajlan2011@gmail.com
}

DOI: https://doi.org/10.31559/LCJS2021.2.1.4 2021/2/3 مراجعة البحث: 2021/2/27 قبول البحث: 2021/4/23

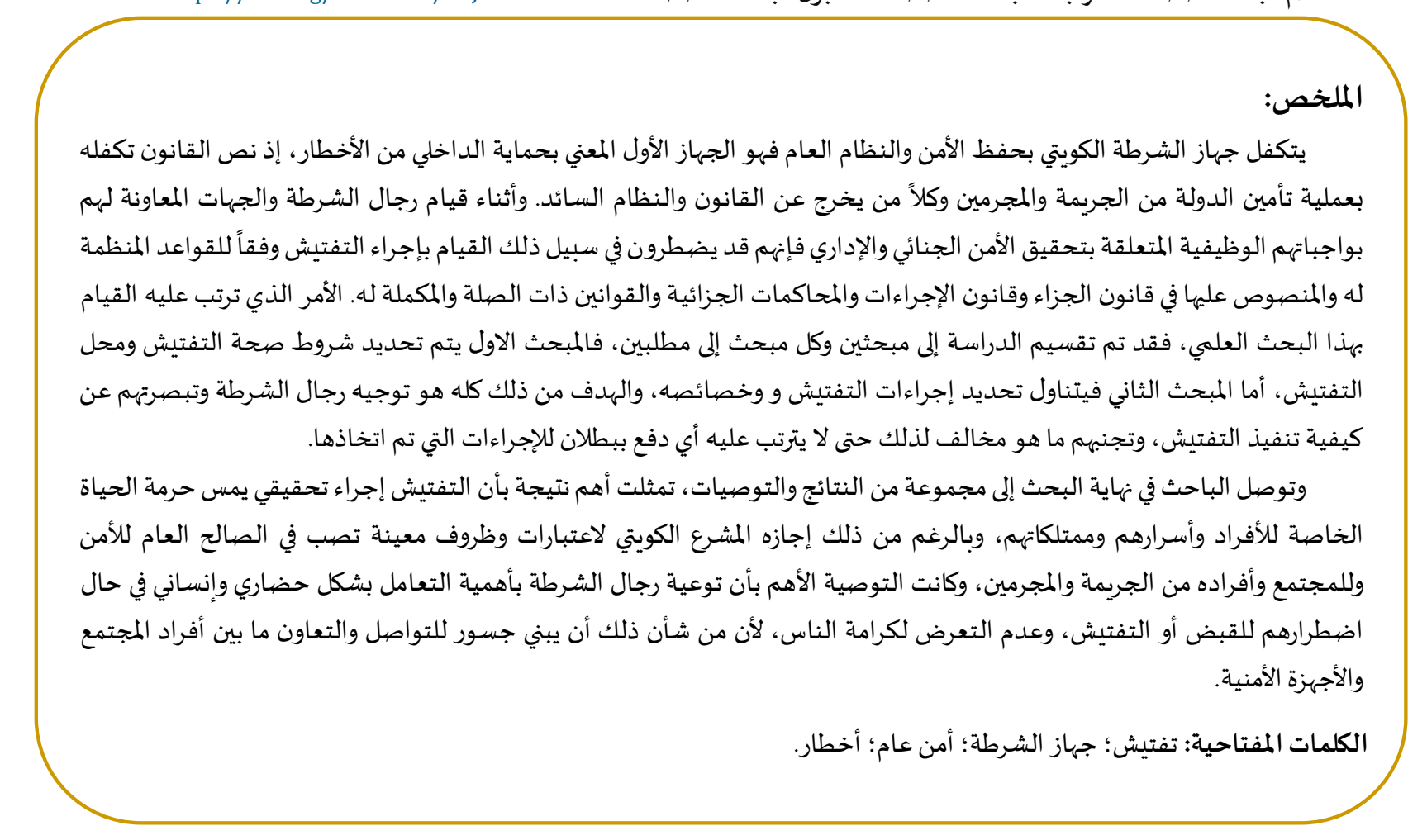

المقدمة:

يهدف قانون الإجراءات الجزائية الكويتي- شأنه في ذلك شأن كافة الدول الحضارية - بشكل عام إلى حماية المصلحة الاجتماعية من خلال ما ينظمها من إجراءات لكشف الحقيقة واقرار سلطة الدولة في العقاب وبواسطة الضمانات التي يقررها لحماية حقوق وحريات المتهم التي تتعرض للخطر من جراء هذه الإجراءات ، ويوازن القانون الجنائي بفرعية بين المصلحة العامة، فيقرر من المصلحتين ما يهم المجتمع ويضمن سيره وفعاليته، ويتوقف ما يهم

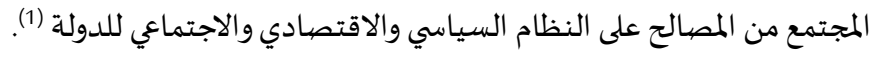

1 د. احمد فتحي سرور، الحماية الدستورية للحقوق و الحريات ، دار الشروق ، الطبعة الأولى ، سنة 1999 ، ص 101. 
وطبقاً لقانون الإجراءات الجزائية الكويتي فإنها في حال وقوع جريمة من نوع الجنايات تختص النيابة العامة بالتحقيق من خلال محققوها المعنيين،

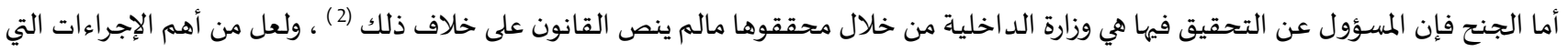

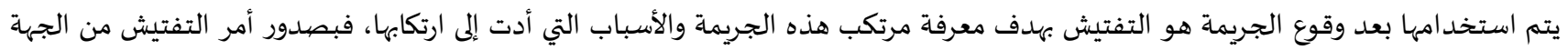

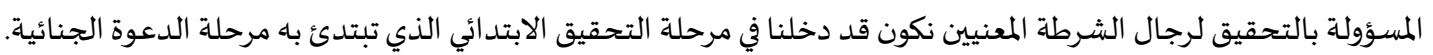

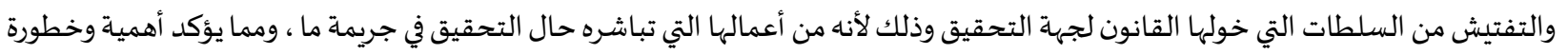

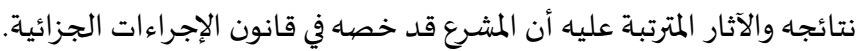

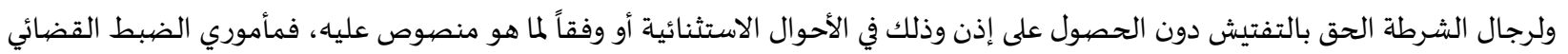

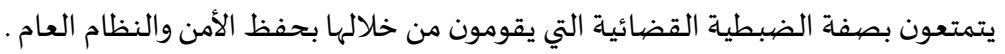

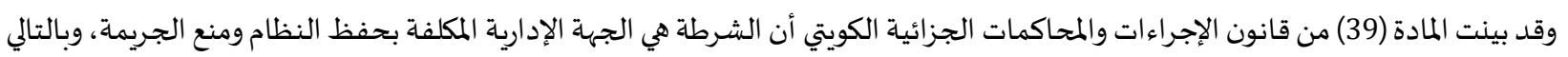
فأن لهم صيفة الضبطية الإدارية .

ماهية التفتيش: أجاز المشرع الكويتي لرجال الضبط القضائي في حال الجريمة المشهودة ووفقاً للقانون الحق بالقبض على المتهم دون إذن مسبق من قبل سلطة

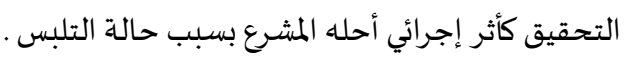

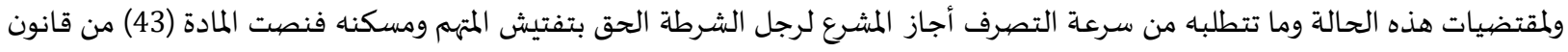

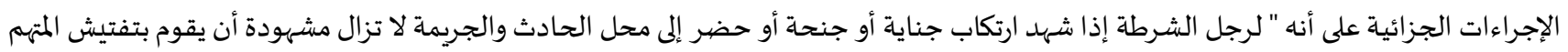
أو مسكنها. ويرى الفقه أن المادة (43) سالفة الذكر -أي الجريمة المشهودة - لا تسري في لبعض الجرائم كجريمة السب والقذف في الطريق العام إذ أن طبيعتها ليس من شأنها ترك أدلة مادية.3. والأصل أن التفتيش عمل من أعمال التحقيق، وبالتالي فإن السلطة التي تباشره هي سلطة التحقيق، ولكن المشرع قد خول رجال الشرطة القيام بهذا العمل على سبيل الاستثناء وذلك من أجل تحقيق الصالح العام، وسرعة الفصل فئ في التحقيق وأعماله، وضبط الأدلة التئي تدين المتهمه، وتفيد في في كشف الحقيقة. والتفتيش بطبيعته يمس حقوق المتهم الشخصية، وهذه الحقوق قد كفلها الدستور الكويتي شأنه في ذلك شأن كافة الدساتير الحضارية، إذ يترتب

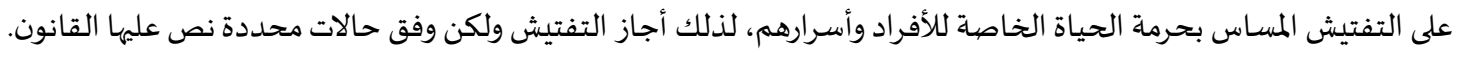

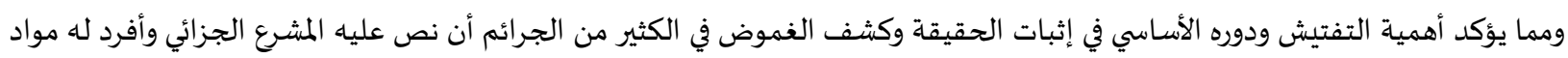

تظهر أهمية البحث عن موضوع التفتيش باعتباره عمل من أعمال التحقيق ولخطورته إلى معرفة الشروط المتعلقة بصحته والتي يمكن من خلالها

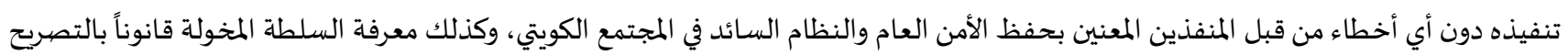
بمثل هذا الإجراء، ومحل التفتيش، وهل يتطلب المشرع إجراءات معينه للقيام بالتفتيش، كما تظهر أهمية البحث تحديد الخصائص التي يتميز بها التفتيش. بمتئ.

مشكلة الدراسـة: تتمثل مشكلة الدراسة أن بعض رجال الشرطة أثناء صيدور الإذن أو الأمر من جهات التحقيق بالتفتيش لأشخاص أو مساكن دارت الشبهات حولهم ألهات

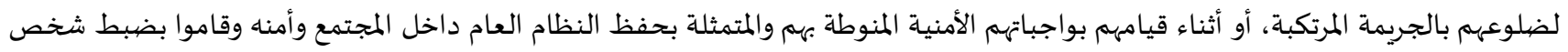

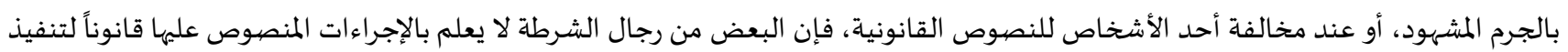

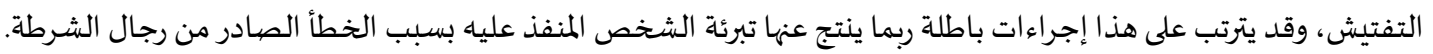

22 انظر المادة (9) من قانون الإجراءات والمحاكمات الجزائية الكويتي.

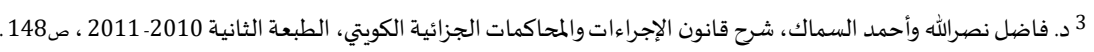
4 انظر المادة 43 والمواد من 78 الى 89 من من قانون الإجراءات والمحاكمات الجزائية الكويتي. 
كما ينتج عنه وبلا شك الاعتداء على الحقوق والحريات التي كفلتها الدستور الكويتي والقانون، وبذات الوقت ينتج عنه الإساءة للصهورة الذهنية

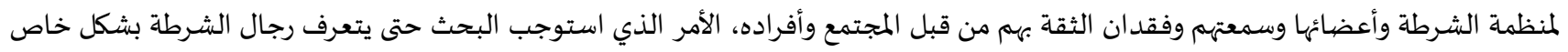

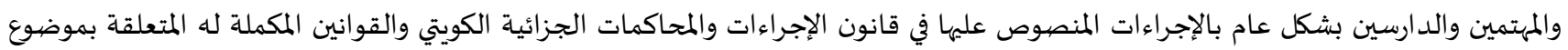

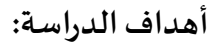

1. تحديد الجهات التي خولها القانون بإصهدار إذن التفتيش.

2. بيان شروط صحة التفتيش.

3. بيان محل التفتيش.

4. معرفة الإجراءات التي يتم من خلالها التفتيش.

5. تحديد خصائص التفتيش.

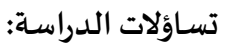

1. هل التفتيش من أعمال التحقيق؟

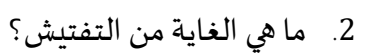

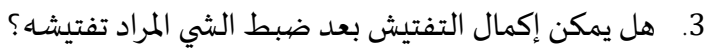

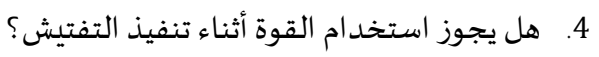

5. كيف يتم تفتيش الأنثى؟

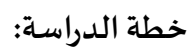

تم تقسم الدراسة إلى مبحثين وكل مبحث إلى مطلبين على النحو التالي: المبحث الأول: شروط صحة التفتيش والمحل التفتيش .

المطلب الأول: شروط صحسة التفتيش.

المطلب الثاني: نطاق إجراء التفتيش.

المبحث الثاني: إجراءات التفتيش وخصيائصيا.

المطلب الأول: إجراءات التفتيش.

المطلب الثاني: خصائص التفتيش. إجراء التهتين.

التفتيش هو أحد الإجراءات التي تقوم باه سلطة التحقيق أو تأمر به وأهمها بهدف الوصول للحقيقة المتعلقة بموضهوع التحقيق وجمع الأدلة التي

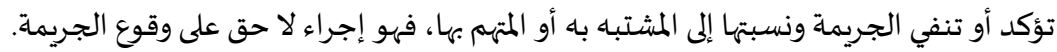

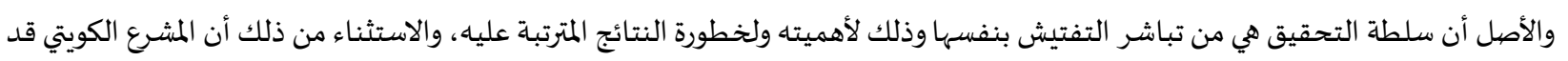

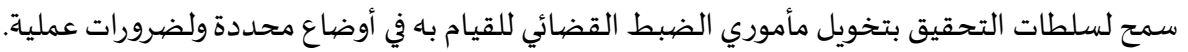
وقد أكد الدستور الكويتي على أهمية عدم التعرض للحقوق والحريات العامة والخاصة في مواده وترك للمشرع الجزائي تنظيم ذلك، وجعلها في

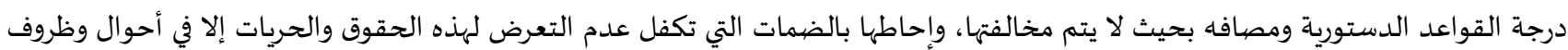
معينة، فالتفتيش وغيره من الإجراءات الجزائية والتي قد ينتج عنها التعرض لحرمة الحياة والحقوق اللصيقة بالشخصية لا تكون إلا وفق ما نص عليه

$$
\begin{aligned}
& \text { وعليه سوف نتناول البحث عن موضوع التفتيش من خلال التقسيم التالي: }
\end{aligned}
$$

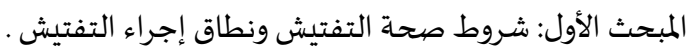

$$
\begin{aligned}
& \text { المبحث الثاني: إجراءات التفتيش وخصائصيا . }
\end{aligned}
$$

5 انظر المواد 30 وما بعدها من الدستور الكويتي. 
المبحث الأول: شروط صحة التفتيش ونطاق إجراء التفتيش

سوف يتم البحث أولاً عن شروط صحة التفتيش، ثم البحث عن نطاق إجراء التفتيش وذلك من خلال التقسيم التالي: المطلب الأول: شروط صحة التفتيش. المطلب الثاني: نطاق إجراء التفتيش.

المطلب الأول: شروط صححة التفتيش

التفتيش إجراء يمس بحرمة الأشخاص وحرمة مساكههم وممتلكاتهم، وقد يترتب عليه نتائج خطيرة، لذلك فإن المحقق لا يأذن بها إلا بتوافر شروط

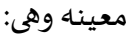

أولاً: تو افردلائل على ارتكاب الجريمة:

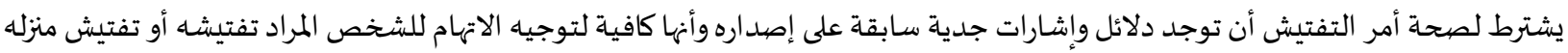
بارتكابه للجريمة موضوع التحقيق وأن بحوزته أشياء متعلقة بالجريمة موضوع التحسيق

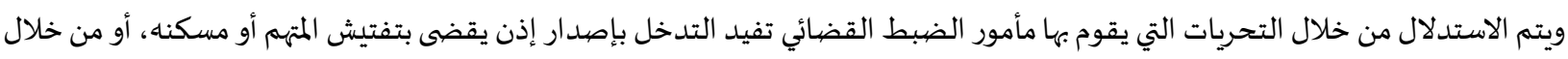
التحقيق الذي يجريه محقق الواقعة، وكذلك من خلال ما توصل إليه المحقق من محاضر التحقيق أو ما وصل إلى علماه من أي مصدر آخر. كما أن البلاغ وحده عن وقوع جريمة لا يكفي لإصدار أمر التفتيش، فيجب أن يقوم مأمور الضبط القضائي بعمل التحريات وجمع المعلومات

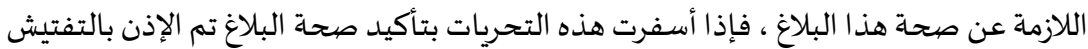
واشتراط وجود دلائل كافية يعد ضمانة من ضمانات المحافظة على الحرية الفردية من أن تمس لمجرد الظن بوقوع الجريمة، فالواجب على المحقق

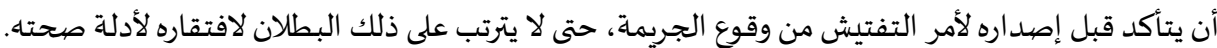
ثانياً: أن تستلزم مصلحة التحقيق القيام به:

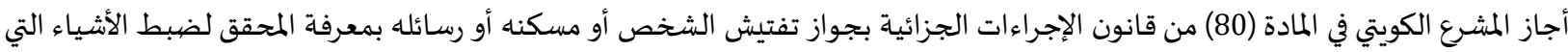
استعملت في الجريماة، أو نتجت عنها، أو تعلقت بها متى استلزم ذلك ضرورة التحقيق، إذا للمحقق أن يأمر بالتفتيش إذا كان هناك فائدة مناه للتحقيق،

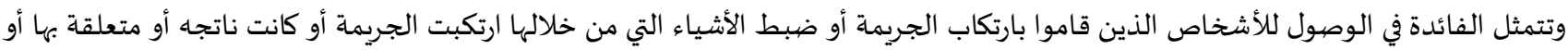
استعملت فيها، ومن ثم معرفة حقيقة الجريمة المرتكبة، كأن يكون أمر التفتيش القصد منه البحث عن ملابس المتهم الملطخة بالدماء أو ملابس المجني علياء الممزقة. وإذا لم يكن هناك فائدة من هذا التفتيش وقع أمر التفتيش باطلاً لأنه لا يكون إلا ضرباً من التحكم، فالتفتيش ليس وسيلة لجمع معلومات عن

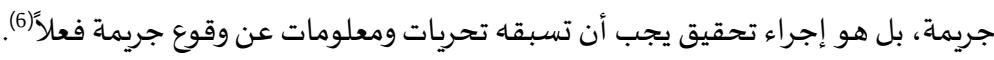
والتقدير الأولي لإصدار أمر التفتيش يكون من صلاء تهلياحية المحقق ، فإذا تبين له وجود فائدة منه أمر به وإلا امتع في حال تبين له عدم وجود فائدة من

ونجد المشرع الإجرائي المصري قد نص في الفقرة الثانية من المادة (91) المعدلة بالقانون رقم 37 لسنة 1972 أنه " في كل الأحوال يجب أن يكون أمر

التفتيش مسببا ".

ثالثاً: عدم وجود طريقة:

تقدم القول بأن التفتيش إجراء تحقيقي يترتب عليه المساس بالحرية الخاصة للأشخاص ومساكنهم، لذلك فان المحقق لا يأمر أو يأذن لرجال

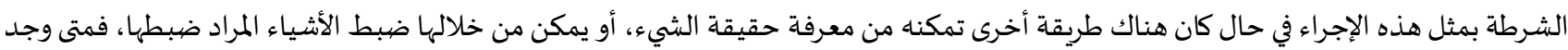

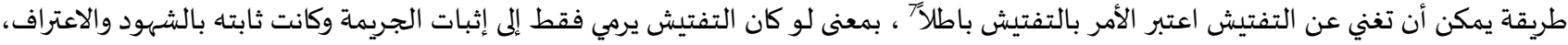

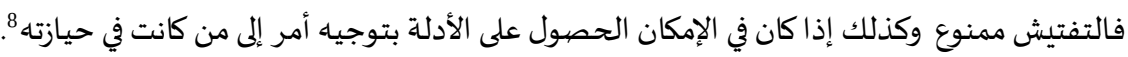

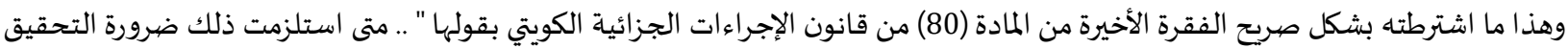

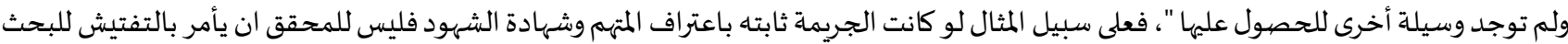
عن أدلة تثبت الجريمة. وبالتالي فإذا كان هناك طريقة أخرى غير التفتيش ومع ذلك أمر المحقق بالتفتيش فان يكون بذلك قد خالف صحيح القانون.

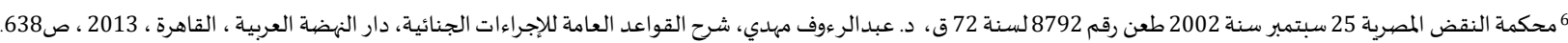
7 7. فاضل نصرالله و د. أحمد حبيب السماك ، شرح قانون الإجراءات والمحاكمات الجزائية الكويتي، مرجع سابق ، ص124.

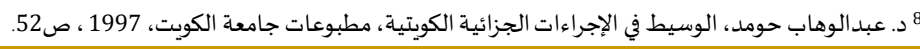


رابعاً: أن يكون الغرض منه ضبط الأدلة موضيوع التحقيق:

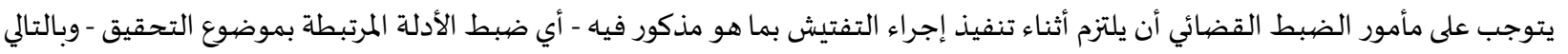

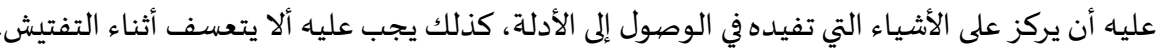
فلو كانت الجريمة المرتكبة هي جريمة قتل، وصدر إذن التفتيش للبحث عن سلاح الجريمة وضبطه كان يكون هذا السلاح مسدس، فإن لمأمور

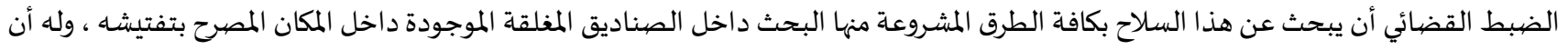
يأمر صاحب هذا المكان في حال كانت هذه الصناديق مغلقة أو أن هناك غرفة مغلقة أو دواليب بفتح الأغفال بقصد ضبط هليط سلاح الجريمة، وعلى هذا الأخير أن يمتثل للأوأمر، وفي ذات الوقت يجب على هانى مأمور الضبط القضيائي ان يحافظ على المكان ومحتوياته ، فلا يتصور أن يقوم بإتلاف الأثاث وغيره من محتويات هذا المكان، بحجة ضبط السلاح المستخدم بالجريمة موضوع التحقيق. المطلب الثاني: نطاق إجراء التفتيش نصت المادة (80) من قانون الإجراءات الجزائية الكويتي على أنه " يجوز تفتيش الشخص أو مسكنه أو رسائله "، يتضح بأن المشرع قد أجاز تفتيش

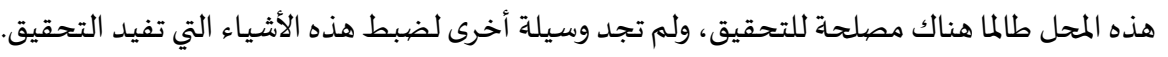
وقد يكون محل التفتيش هو المتهم او مكانه أ رسائله، ويكون ذلك بأمر من المحقق أو بإذن منه لأحدد مأموري الضبط القضائي، أو قد يقوم هو باه

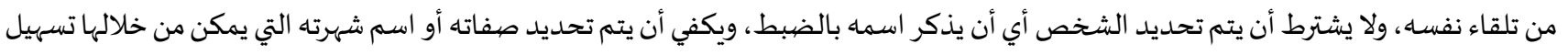

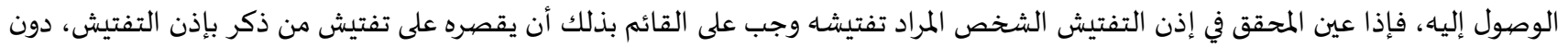

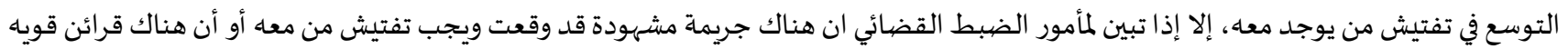

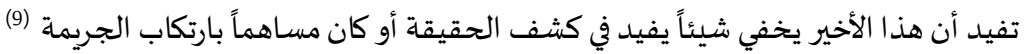
وبينت المادة (43) من قانون الإجراءات الجزائية الكويتي أنه لرجل الشرطة الحق بتفتيش المتهم و مسكنهاه في حال الجريمة المشهودة وذلك بنصها

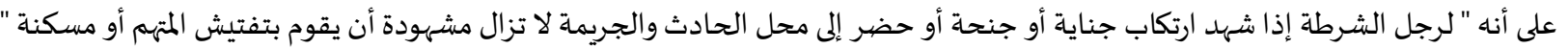

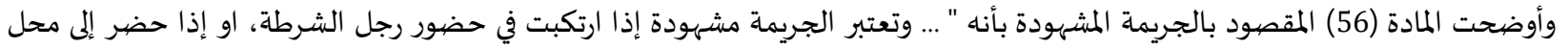

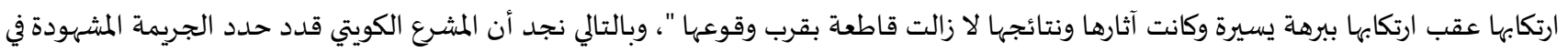
الحالتين المذكورة في المادة (43) وهي على سبيل الحصري، كذلك أنه خول لرجال الشرطة في ذلك سلطة مباشرة بعض إجراءات التهاء التحقيق وهي على سبيل

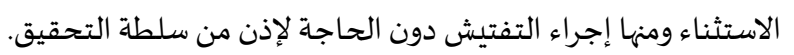

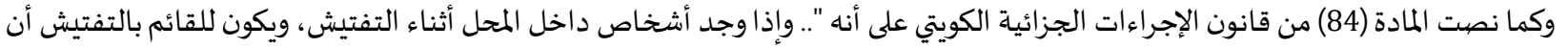

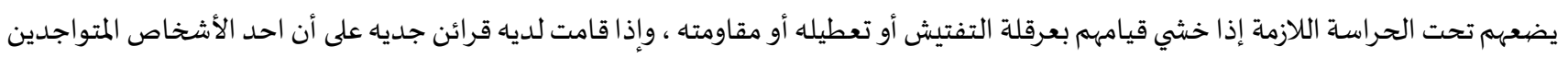

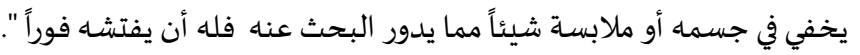

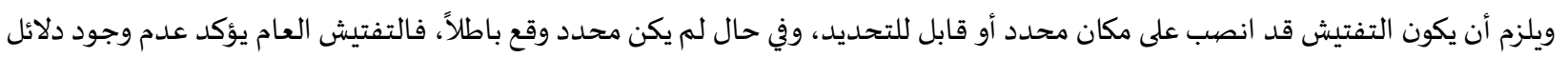

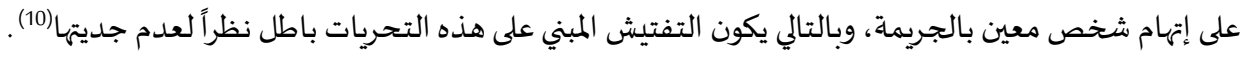

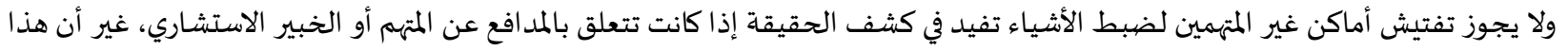

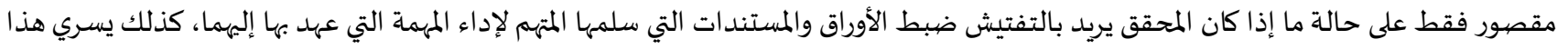

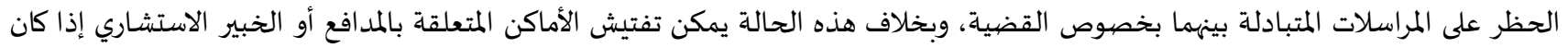

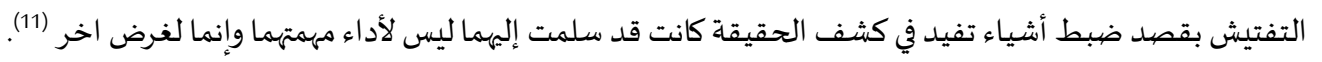
تفتيش الأشخاص: يقصد بتفتيش الأشخاص البحث في أجزاء جسم الشخص وملابسها وحقائبه أو الأشياء التي يحملها أو تكون في حيازته، بقصد العثور على الأدلة

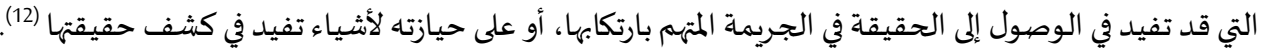

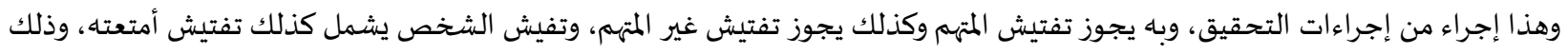
على النحو التالي:

9د. فاضل نصرالله ، د. احمد حبيب السماك ، مرجع سابق ، ص 127.

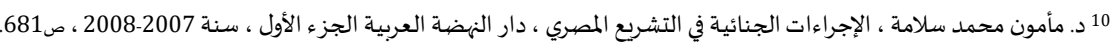

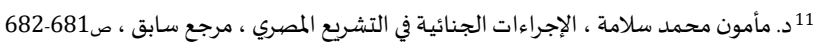

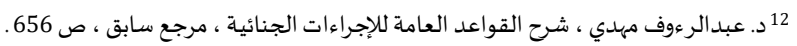


تفتيش المتهم:

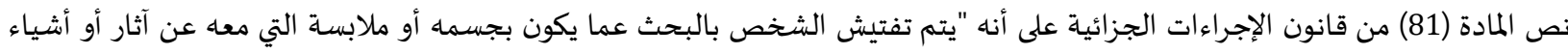

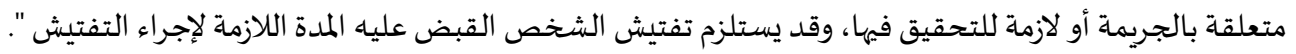

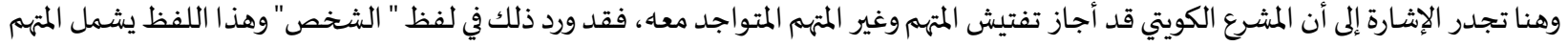

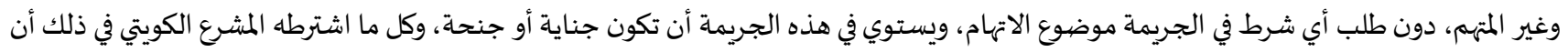

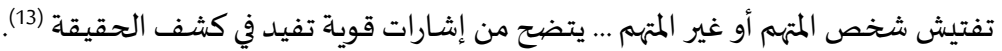

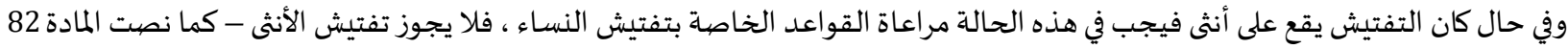
إجراءات جزائية كويتي - إلا بمعرفة أنثى (14)، كذلك يجب مان مراعاة القواعد الخاصة بالمحافظة على أدمية الفرد وانسانيته وذلك بعدم التفتيش بالأماكن التي تمس تلك القيم. ولا يجوز تفتيش بعض الأشخاص الذين يتمتعون بحصانة خاصة، كالدبلوماسيين وأعضاء النيابة العامة والقضاة وأعضاء مجلس الأمة، فلا يصح تفتيشهم في الظروف العادية إلا طبقاً لشروط معينة يجب استيفائها قبل التفتيش. وعليه يمكن أن نحصر شروط صحة تفتيش الأشخاص فيما يلي (15): 1. أن يكون هناك أمر صادر من المحقق لأحد مأموري الضبط القضائي بالقيام بالتفتيش أو أن هناك حالة تلبس التي تبيح لمأموري الضبط القضائي القيام بالتفتيش دون أمر من سلطة التحقيق .

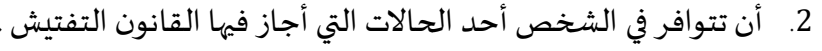
3. أن أنون التفتيش ضرورياً.

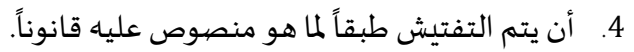

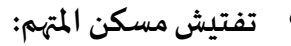
المسكن هو المكان الذي يسكن فيه الإنسان ويطمئن في كونه مستودعاً لسر، فلا يجوز الاطلاع عليه أو على ما بداخله إلا في أحوال معينة نص عليها القانون أو برضاء صاحب هذا المسكن.

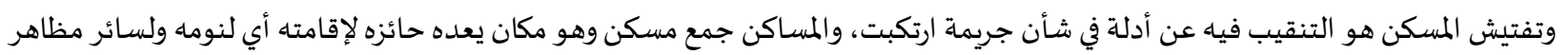

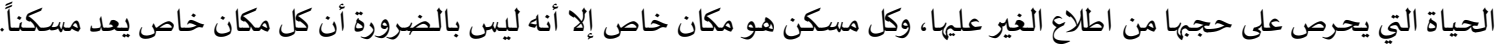

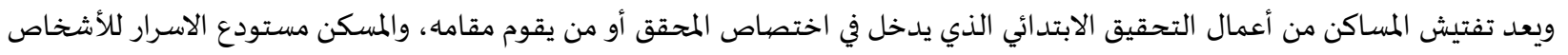

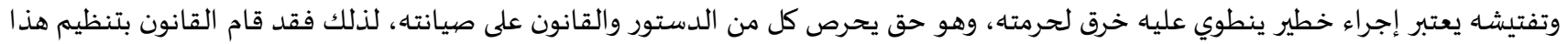

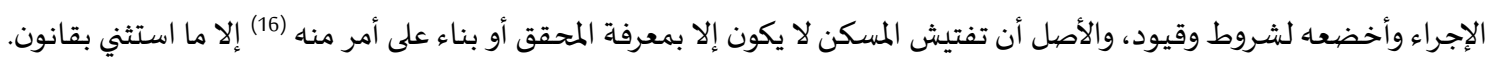

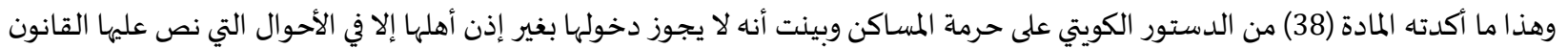

وبينت المادة (78) من قانون الإجراءات الجزائية بأن المسكن يشمل كل مكان مسور أو محاط بأي حاجز مستعمل أو معد للاستعمال كمأوى.

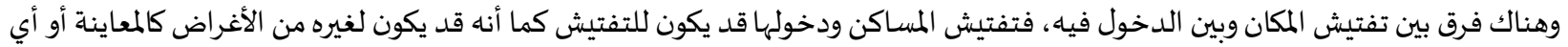

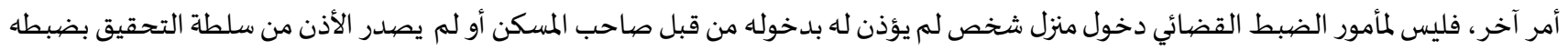

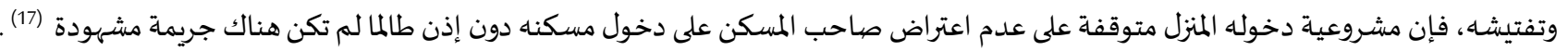

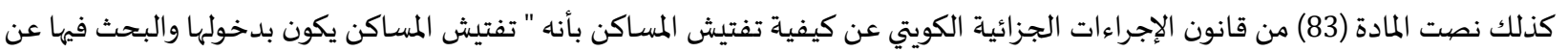

شيء أو اثر يفيد التحقيق أو يلزم له، وللقائم بتفتيش المسكن أن يبحث عن الأشياء المطلوب ضبطيها في في جميع أجزاء المسكن وملحقاته ومحتوياته ".

13 د د. فاضل نصر الله ، د. احمد حبيب السماك ، مرجع سابق ، ص 129.

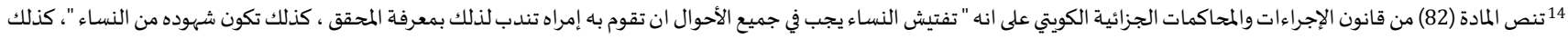

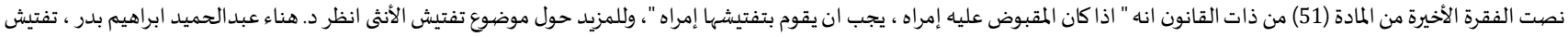

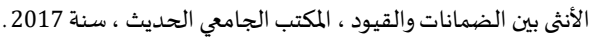

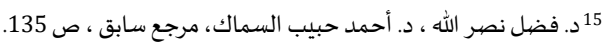

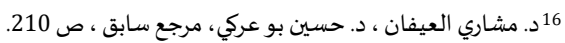

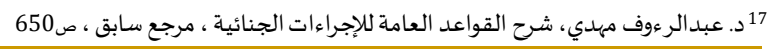


ويكون تنفيذ تفتيش المساكن كما جاء في نص المادة 85 من قانون الإجراءات الجزائية نهاراً فلا يجوز ذلك ليلاً أو بدون استئذان أصحاب المكان، إلا

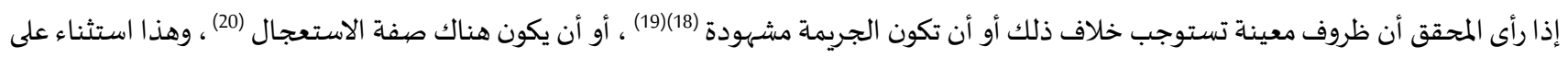

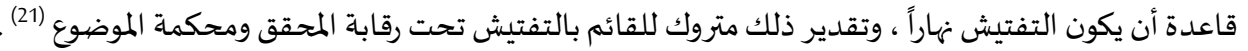
وإذا كان في المسكن نساء محجبات ولم يكن الغرض من الدخول ضبططهن ولا تفتيشهن وجب على القائم بالتفتيش أن يمكنهن من الاحتجاب ويسهل

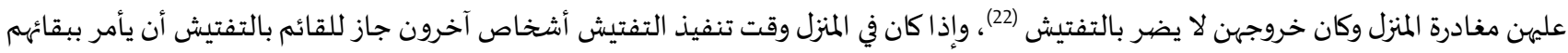

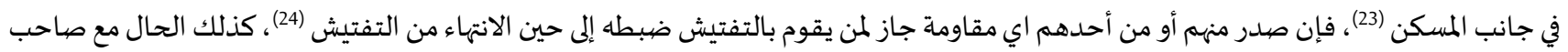

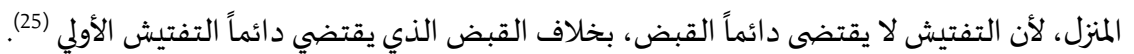

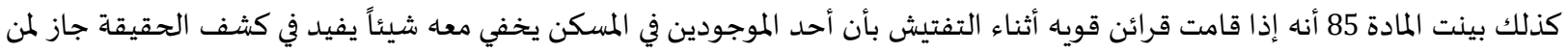

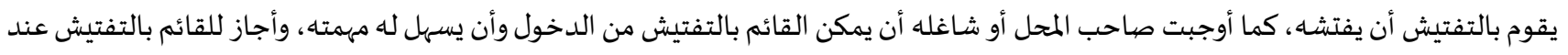
رفض السماح له بالدخول أو مقاومة دخوله أن يقتحم المسكن وأن يستعمل وسائل القوة اللازمة للدخول ولو بكسر الأبواب أو التسلق، أو ما يماثل

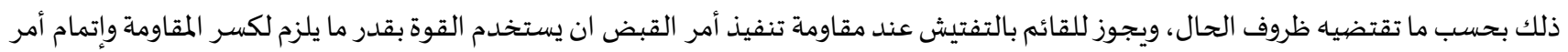

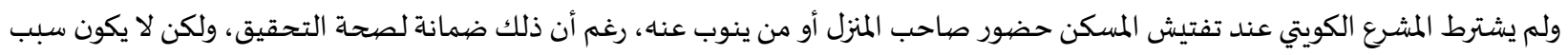

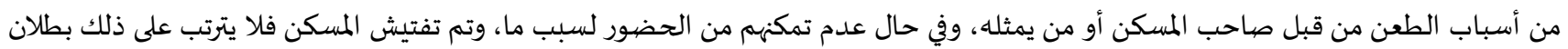

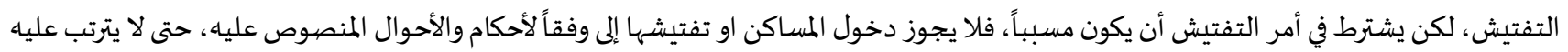
أي دفع بالبطلان (26). وإذا وجدت الأشياء الجاري البحث عنها يتم ضبطها، ويتب حفظها بدقة وأمانة، وإذا وجدت أشياء أخرى غير المطلوب البحث وتعتبر حيازتها جريمة

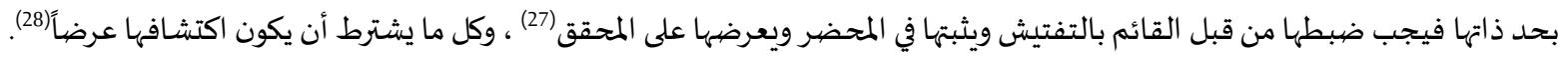

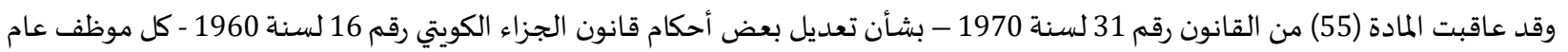

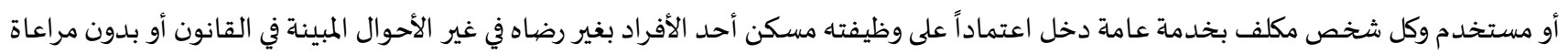
القواعد والإجراءات المبينة فيه، يعاقب بالحبس مدة لا تجاوز ثلاث سنوات وبغرامة لا تجاوز 225 دينار أو بإحدى هاتين العقوبتين .

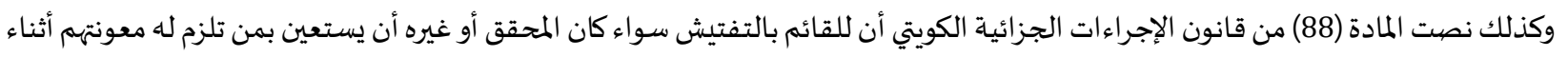

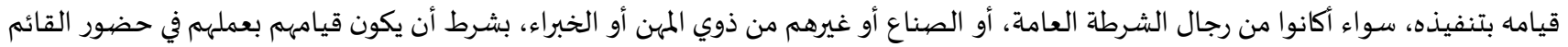
بالتفتيش وتحت إشرافه ومسؤوليته.

\section{تفتيش الرسائل وضبطها :}

نصت المادة (39) من الدستور الكويتي على أنه " حرية المراسلات البريدية والبرقية والهاتفية مصونة، وسريتها مكفولة، فلا يجوز تفتيش الرسائل أو

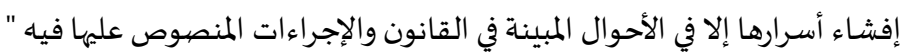
يتضح من النص السابق بأن المشرع الدستوري الكويتي قد سار على نهج أغلب الدساتير الديموقراطية التي تجعل للمراسلات - أياً كانت صورتها -

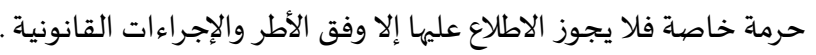

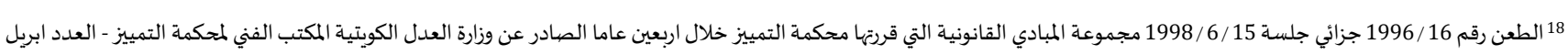
$206-2015$ 19 الطعن رقم 100 / 2004 جزائي جلسة - 11 / مجموعة المبادي القانونية التي قرتها محكمة التمييز خلال اربعين عاما الصادر عن وزارة العدل الكويتية المكتب الفني لمحكمة التمييز - العدد ابريل 2015- ص207. 20 المادة (85) من قانون الإجراءات والمحاكمات الجزائية الكويتي.

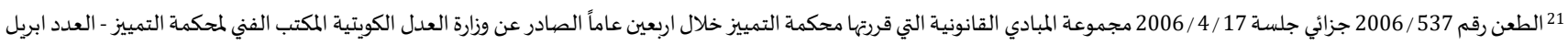
208 -2015 22 انظر المادة (86) من قانون الإجراءات والمحاكمات الجزائية الكويتي.

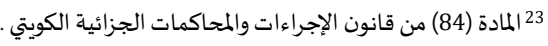

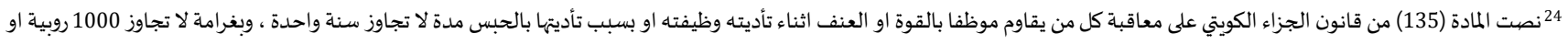




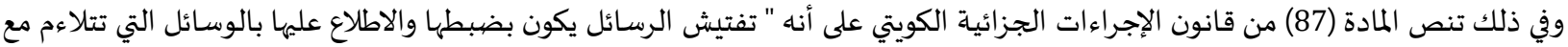

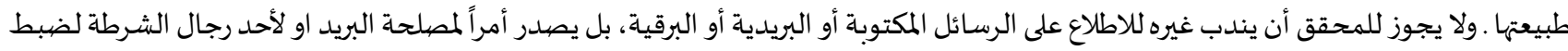

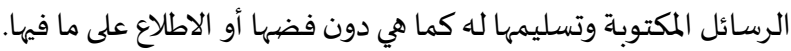

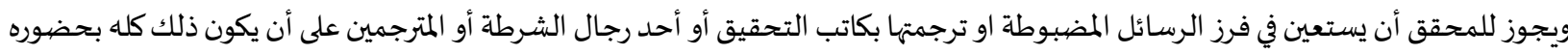
وتحت إشرافه.

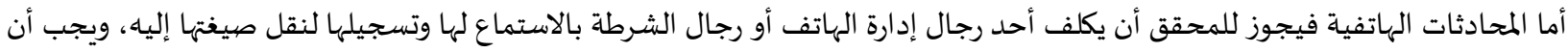

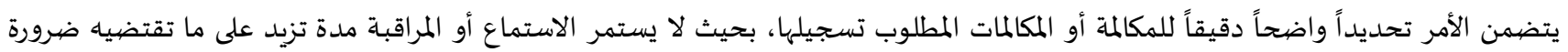

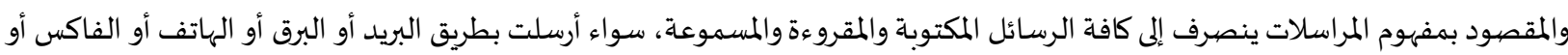

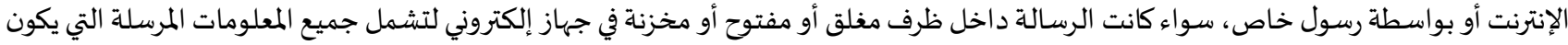

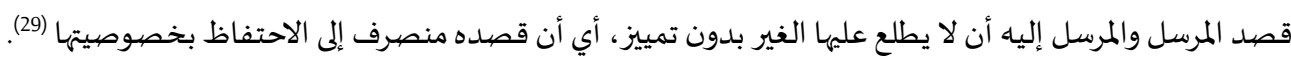

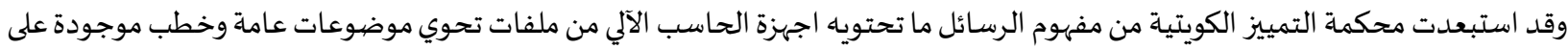

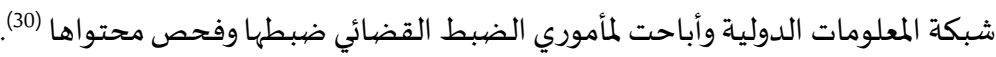

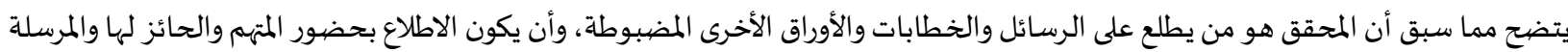

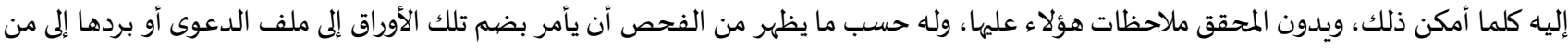

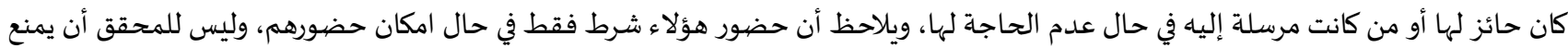

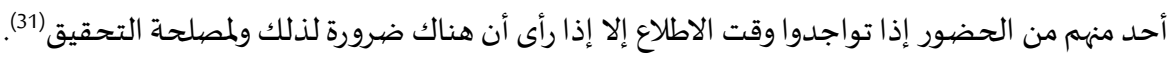

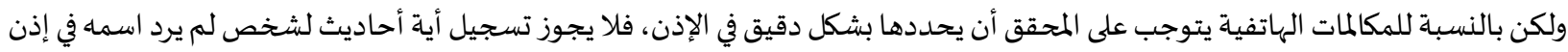
تسجيل المكالمات الهاتفية، أما وقد تم تسجيلها فإن هذا التسجيل يكون وليد إجراء غير مشروع لم يأذن به ويكون الدفح ببطلان الدليل المستمديد منهاه في

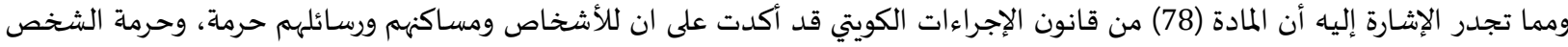

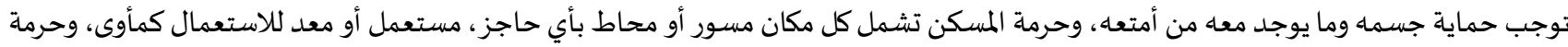

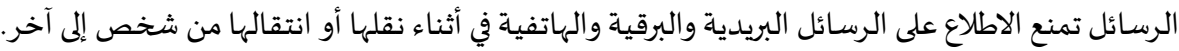

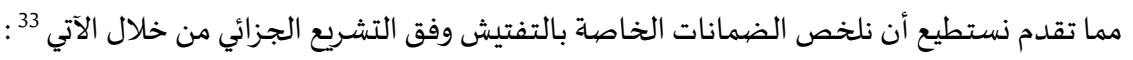
1. يجب أن يباشر المحقق بنفسه التفتيش أو بواسطة أحد مأموري الضبط القاطئ القضائي.

2.

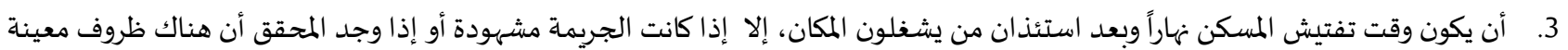

$$
\text { تستوجب الاستعجال بالتفتيش. }
$$

4. إخطار الشخص المطلوب تفتيشه أو تفتيش محله من قبل القائم بتنفيذ أمر التفتيش بصدور أمر بذلك، وأن يطلعه على أمر التفتيش في حال طلب الشخص ذلك ( المادة 63 و المادة 68 من قانون الإجراءات الجزائية).

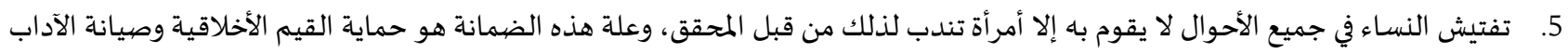
العامة وعرض الأنثى ولو كانت متهمة.

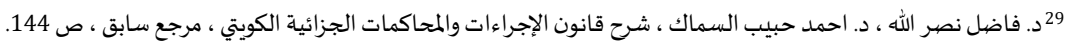

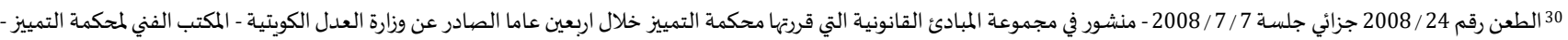

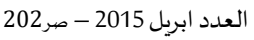

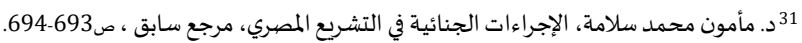

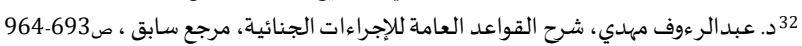

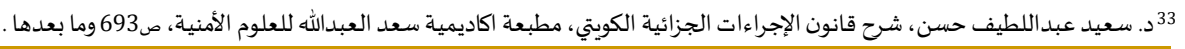


المبحث الثاني: إجراءات التفتيش وخصيائصيه

سنتناول في المطلب الأول الحديث عن إجراءات التفتيش، ثم ننتقل للحديث عن خصائص التفتيش في المطلب الثاني.

$$
\text { المطلب الأول: إجراءات التفتيش }
$$

يشترط لمباشرة إجراء التفتيش أن يكون بعد وقوع الجريمة وليس قبل وقوعها، وهو من الصلاحيات التي منحها المشرع للمحقق، فالمحقق هو من

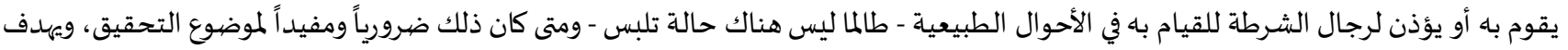
إلى كشف وضبط أدوات الجريمة ومرتكبيها. • • • • إصيدار إذن بالتفتيش من المحقق وكتابته:

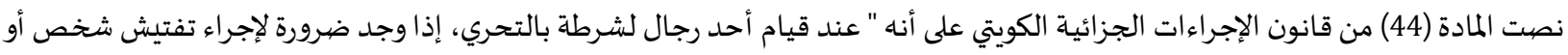

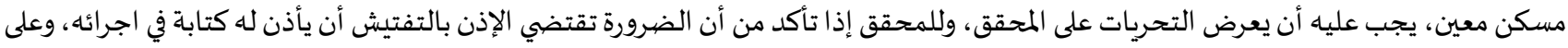

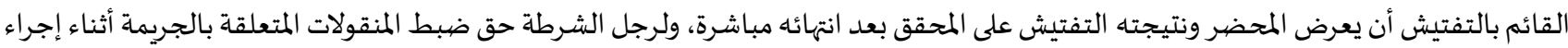
التفتيش او التحريات ".

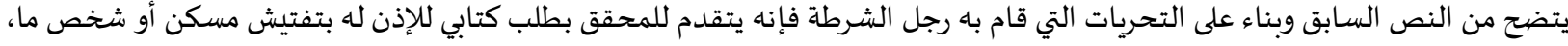

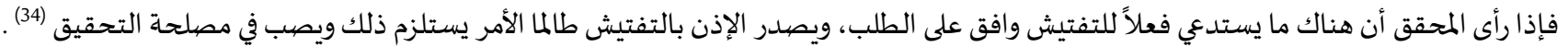
كما يتبين من النص أن للمحقق رفض الطلب الذي تقدم باء رجل الشرطة في حال عدم جدية التحريات التي قام بها، فهذا الأمر من صهلاحيات

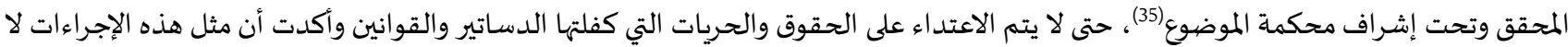
تتم إلا لضرورات معينة وفي أحوال محددة.

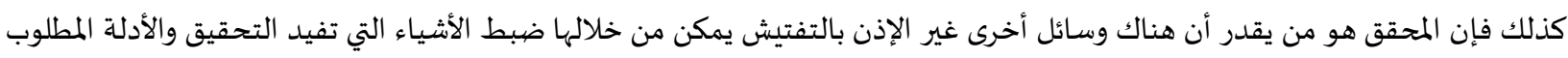
الحصول عليها، فقد يعترف المتهم عند المحقق عن الجريمة الواقعة، وكذلك قد يقوم بتسليم الأدوات التي استخدمت في الجريمة أو نتجت عنها، لذلك فقد يرى المحقق عدم وجود ضرورة للإذن بالتفتيش.

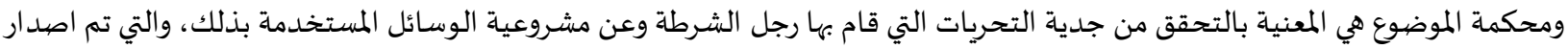

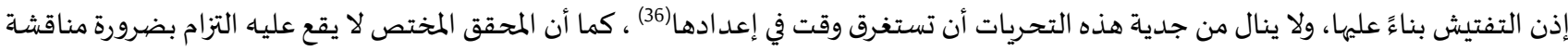

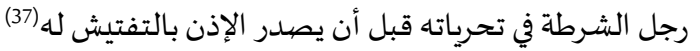
ويجب أن يكون اذن التفتيش كتابياً ويحرر من نسختين على أن تسلم احد أهما للقائم بالتنفيذ والأخرى تكون بمحضير التحقيق، ويتعين أن يتضمن

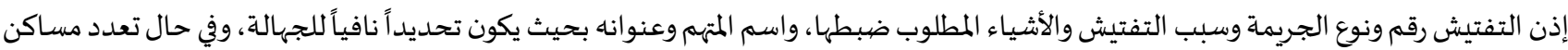
المتهم يججب أن يحدد بالإذن المسكن المطلوب تفتيشها، وفي حال عدم تحديد المسكن في إذن التفتيش فإنه يشمل جميع مساكن المتهم طالما أن دليل

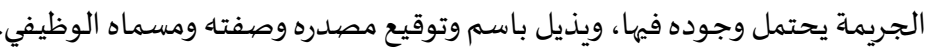

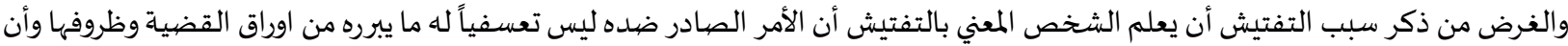

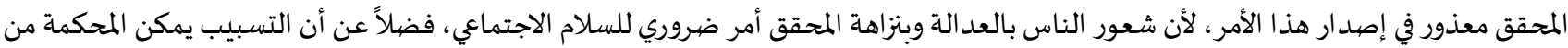
مراقبة مدى سلامة صدور أمر التفتيش، ومع ذلك لو أن المحقق إصدر إذن بالتفتيش لأحد مأمور الضبط القضائي لتنفيذه فلا يشترط أن يكون أمره 
التصبرف بالمضببوطات الجرمية وفقاً للقانون:

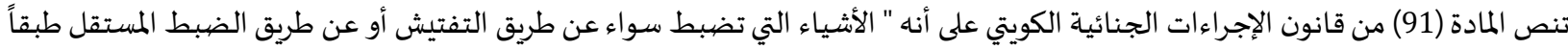

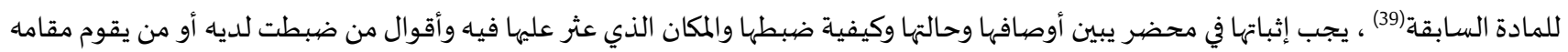
بشأها.

وتوضيع المضبوطات في احراز تتناسب مع حجمها وطبيعتها، وتلصق عليها ورقة تبين تاريخ الضبط ومكانه وسببه والقضية المتعلقة بها وتوقيع من قام وتتم هذه الإجراءات قبل مغادرة المكان الذي حصل بها الضبط كلما كان ذلك ممكناً، ولمن ضبطت عنده الأشياء الحق في أن يأخذ بياناً بالمضبوطات،

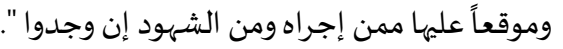

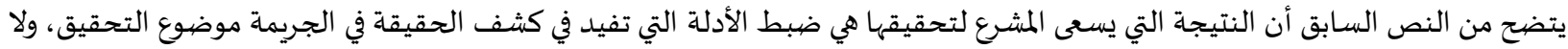

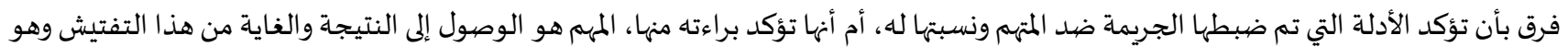

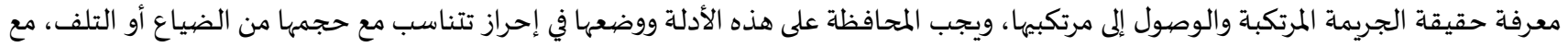

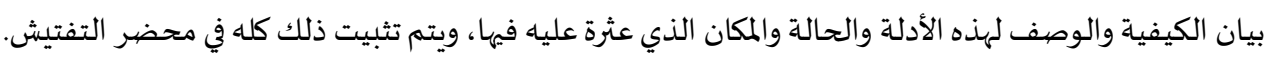

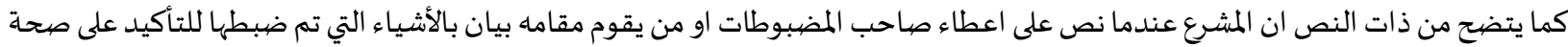

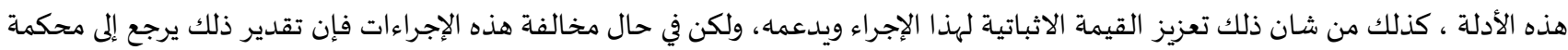
الموضوع مثل كافة الأدلة الأخرى التي تعرض عليها. وعليه نخلص مما سبق أن الهدف من التفتيش هو معرفة حقيقة الجريمة الواقعة ومرتكبيها، وذلك من خلال ضبط الأشياء التي نتجت عنها أو الوضا

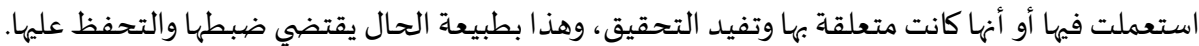

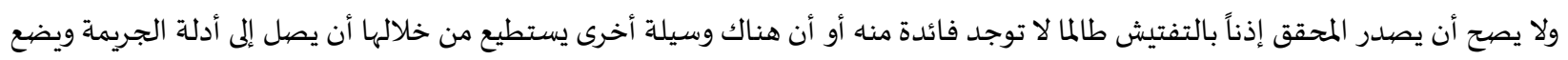

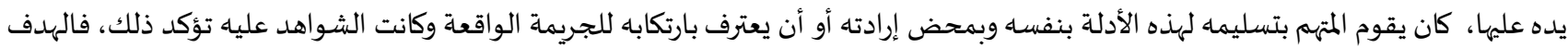

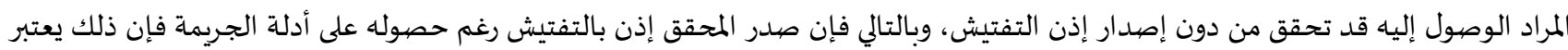

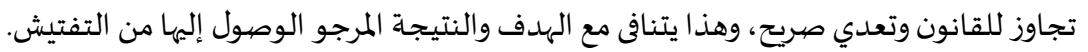

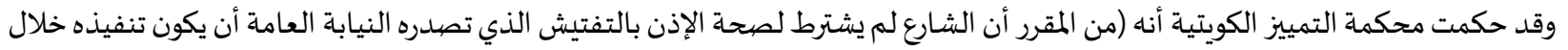

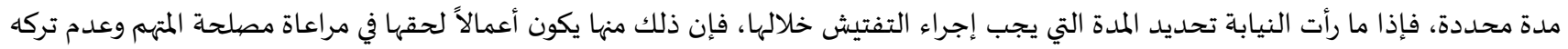

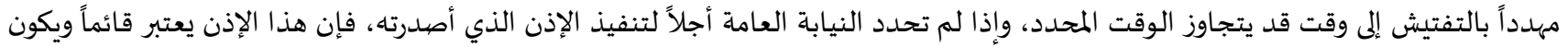

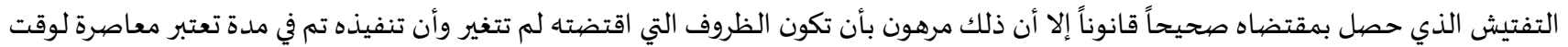
صدور الإذن (40).

$$
\text { المطلب الثاني: خصيائص التفتيش }
$$

ينفرد التفتيش بخصائص معينة تميزه عن باقي الإجراءات الأخرى، فهو إجراء لاحق وبعد وقوع الجريمة، وهيهدف إلى ضبط أدلة الجريمة ، الأمر الذي

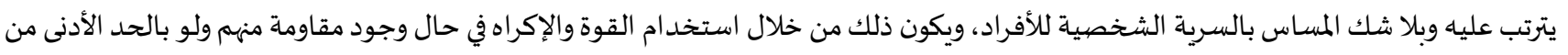
ذلك، إذا تتمثل خصائص التفتيش بالتالي:

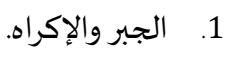

2. المساس بحق الخصيوصية.

3. البحث عن أدلة الجريمة المادية.

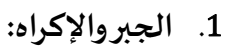

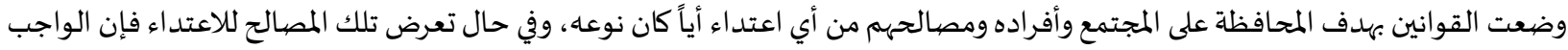

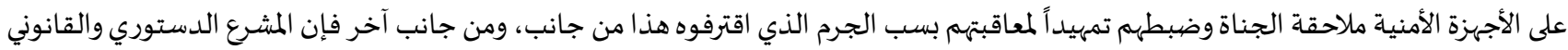

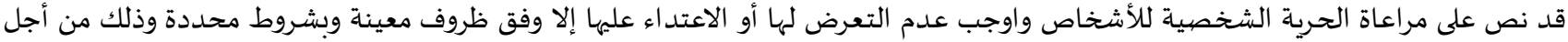

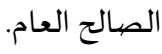

39 انظر المادة (90) من قانون الإجراءات الجزائية الكويتي.

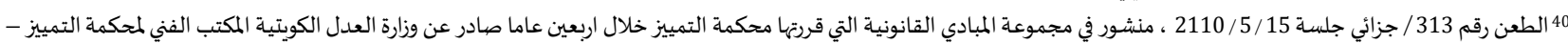


والتفتيش باعتباره من أعمال التحقيق الابتدائي فإنه المتهم يجبر على القيام بهذا الإجراء ضده في حال الرفض، ويستخدم معاء القدر اللازم من

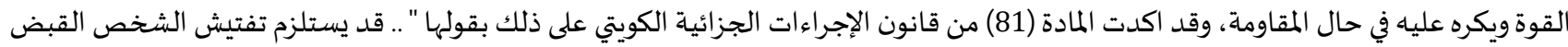

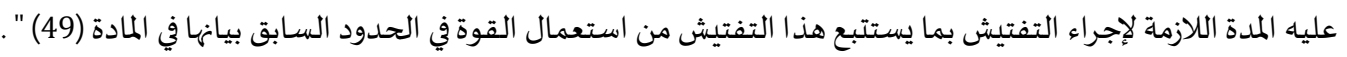

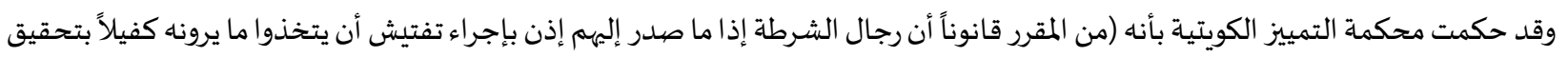

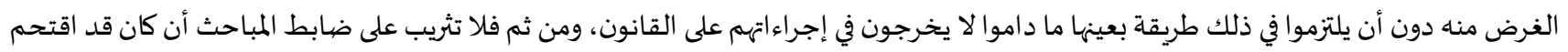

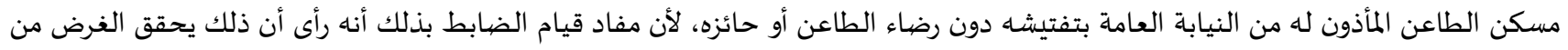
التفتيش، ويكون منعى الطاعن في ذلك غير قويم، ولا على الحكم أن لم يعرض لهذا الدفاع الدهاء بحسبانه دفاعاً قانونياً ظاهر البطلان (41) .

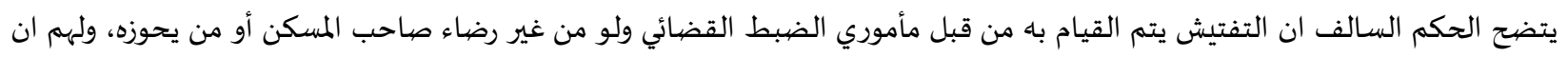

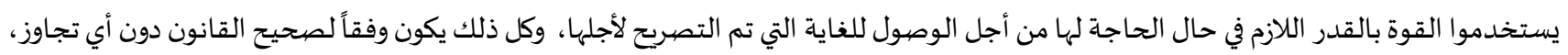

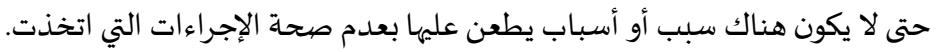

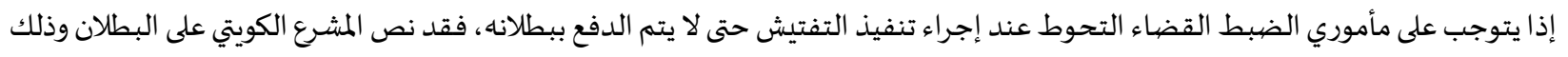

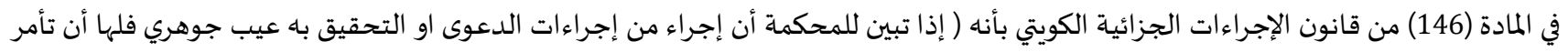

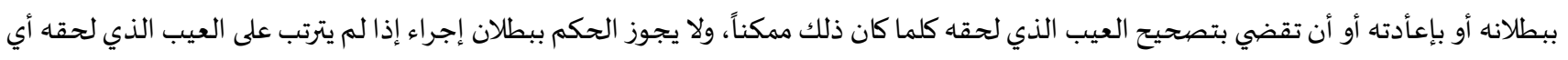

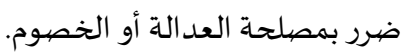

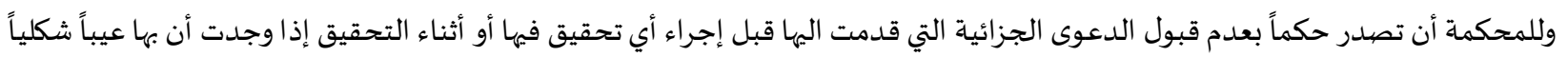
جوهرياً لا يمكن تصحيحه ولا إعادة الإجراءات المعيبة " . ومن النص السابق يتضح التالي 42 •أن المشرع الكويتي قد أعطى المحكمة الحق ببطلان الإجراءات إذا تبين لها أن إجراء من إجراءات الدعوى أو التحقيق باء عيب جوهري، وهو ما يبين

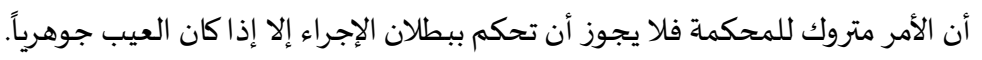

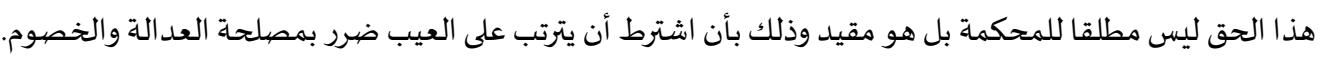
كما أجازت للمحكمة أن تقضي بتصحيح العيب الذي لحق الإجراءات كلما كان ذلك ممكناً وذلك بإزالها لذلك الضرور.

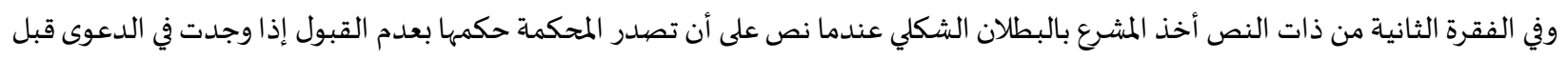

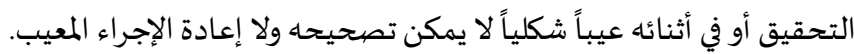

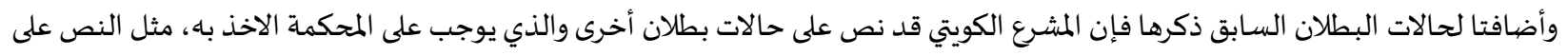

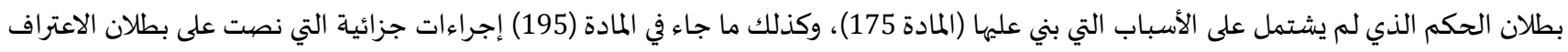
الذي يكون وليد إكراه أو تعذيب، أيضاً النص على بعض القواعلى التهد الشكلية التي بينها القانون وتطلب توافرها في الكثير من الإجراءات حتى لا يترتب عليها

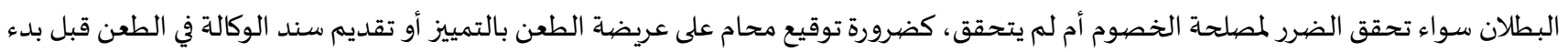

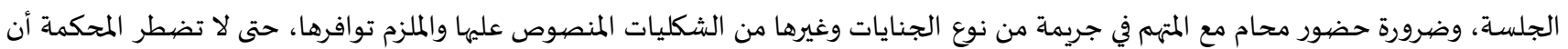

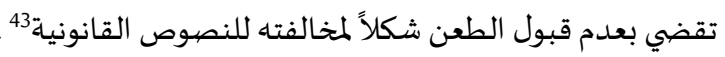

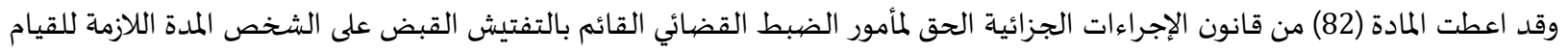
بإجراء التفتيش واستعمال القدر اللازم من القوة في التفتيش. 2.

الأصل ان لكل إنسان حياته وأسراره الخاصة التي يحتفظ بها ولان يرغب في غالب الأحيان أن يطلع عليها الناس، وله الحق في حرمة المسكن وحرية

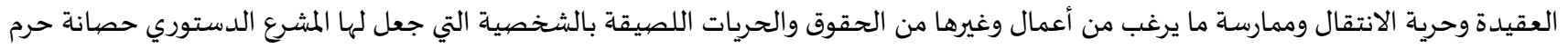
الاعتداء عليها.

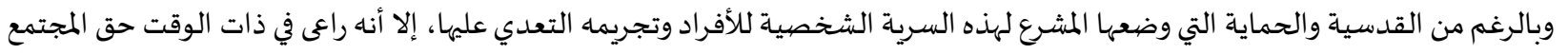
وأمناه، فالحق بالخصوصية يقيد في حال التعدي على حقوق الأخرين، فالمشرع أجاز في غير الأحوال الطبيعية ووفقاً للإجراءات القانونية والتنظيمية

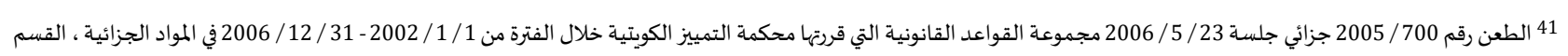

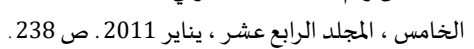

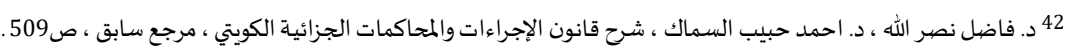

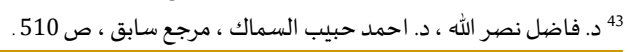


بتفتيش الأشخاص ومساكنهم ومراسلاتهم، فقد أباح التعرض لأسرار الأفراد ولحياتهم الخاصة طالما أن هناك جريمة قد وقعت وأن البحث يجري لمعرفة

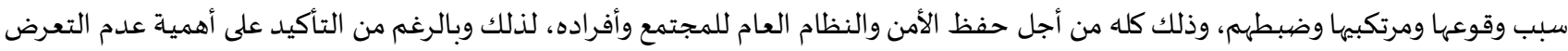

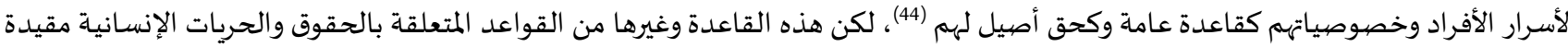
هي الأخرى بضوابط استثنائية يتم اللجوء إليها عند الحاجة لهاء وفيا. 3. البحث عن أدلة الجريمة المادية:

الغاية من التفتيش هو تحقيق الفائدة معينة والتي تتمثل في ضبط الأشياء التي تفيد في كشف الحقيقة بالجريمة التي صدر أمر التفتيش بشأهها،

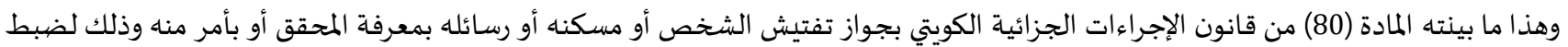

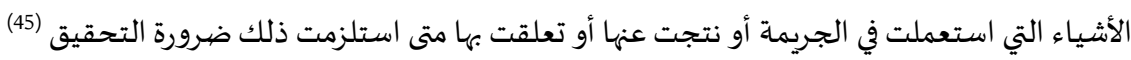

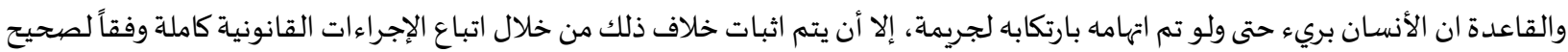
القانون ، ومن أجل إسناد التهمة إلى شخص معين فان ذلك يتوجب الحصول على دليل ضده، لذهلك شُرع القيام بالتفتيش كوسيلة للتنقيب عن الأدلة

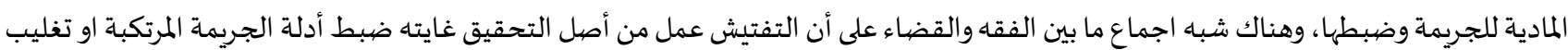
ارتكابها واسنادها إلى شخص محدد (46) . وفي حكم لمحكمة النقض المصرية (47) أن التفتيش ليس وسيلة لجمع المعلومات عن جريمة، بل هو إجراء تحقيق يجب أن تسبقاه تحريات ومعلومات

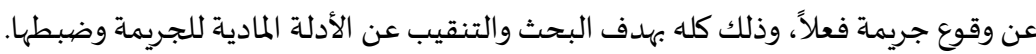

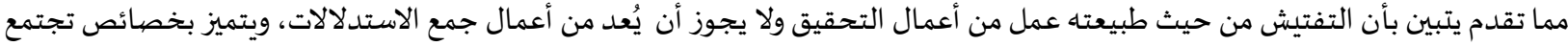

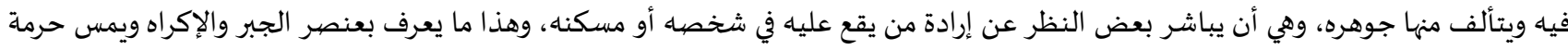

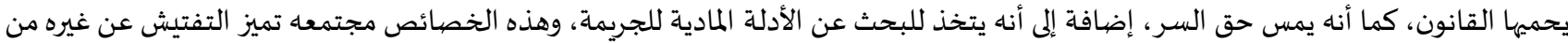
الإجراءات كالاستجواب والمعاينة والضبط وأعمال الخبرة (48) .

النتائج والتوصيات: توصل الباحث في نهاية البحث إلى مجموعة من النتائج والتوصيات، نتناولها من النحو التالي: أولاً: النتائج:

التفتيش كإجراء تحقيقي يمس بحرمة الحياة الخاصة للأفراد وأسرارهم وممتلكاتهم، ومع ذلك أجازه المشرع الكويتي لاعتبارات وظروف معينة تصب

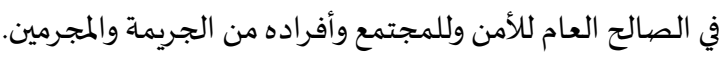
سلطة التحقيق لا تأمر رجال الضبط القضائي القيام بإجراء التفتيش في حال كان هناك طرق أو طريقة أخرى يمكن خلالها التوصل للأشياء المراد ضبطها حتى لا يترتب على ذلك أي بطلان. قد يتطلب التفتيش القبض على الشخص المراد تفتيشها ومن يتواجد معاه لمدة معينة للقيام بالتفتيش، وهذا ما بنته المادة 81 من قانون الإجراءات

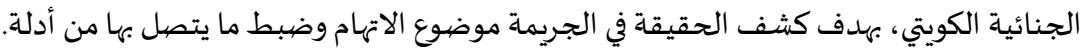
يقوم المحقق بالموافقة على طلب رجال الشرطة بالإذن لهم بتفتيش شخص أو مكان معين وذلك بعد أن دلت جدية التحريات بأن هناك ضرورة للقيام بهذا الإجراء ولمصلحة بالموام التحقيق. يتوجب على رجل الشرطة الحاصل على إذن التفتيش أن يعرض نتائج ذلك مباشرة على سلطة التحقيق وبيان إن كان هناك أي مضبوطات متعلقة

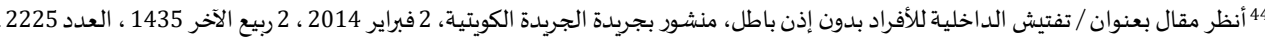

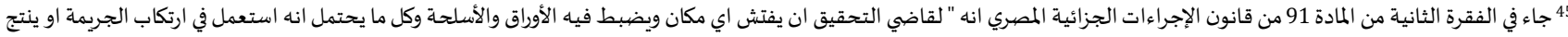

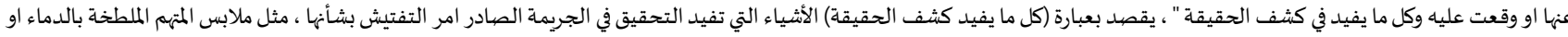

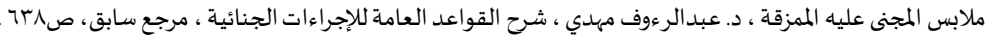

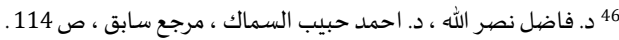

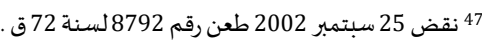

48 مجلة كلية التدربب والتنمية اككاديمية الشرطة بجمهورية مصر العربية ، العدد 36 ، مارس 2002 ف 2017 ، ص15 
يتعين على القائم بالتفتيش في حال تم ضبط أي مضبوطات تتعلق بموضع الجريمة إثبات ذلك في محضر يبين أوصافها وحالتها ومكان ضبطها وأقوال من ضبطت عنده أو من ينوب عنه، وأن يقوم بوضعها في إحراز تتناسب مع حجمها الطبيعي، مع وضع ملصق على الحرز يبين ما يحتوياه ثم يقوم بالتوقيع علياء، ويحق للطرف الآخر صاحب المكان أن يطلب بيان بهذه الأشياء ممن قام باء.

ثانياً: التوصيات:

الأصل العام إن إجراء التفتيش لا يصح إلا إذا كانت هناك جريمة قد وقعت، والدلائل والاتهامات تؤكد ذلك ونسبتها إلى شخص معين، وأن دليل

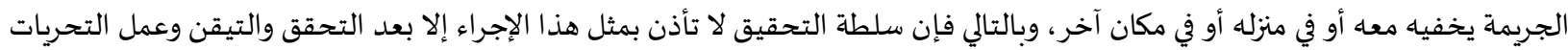

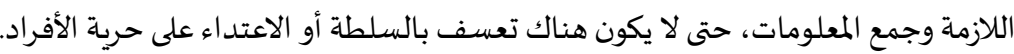
يبطل التفتيش في حال وجود وسيلة أخرى يستطيع المحقق من خلالها الحصول على أدلة الجريمة الواقعة، وفي حال لا توجد وسيلة أخرى يتم إجراء التفتيش. أثناء تفتيش المنازل أو الأشخاص يتوجب على القائم بالتفتيش أخذ القوة اللازمة للقيام باه، لحماية نفساه ومن معهه من أي اعتداء أو مقاومة، ومن

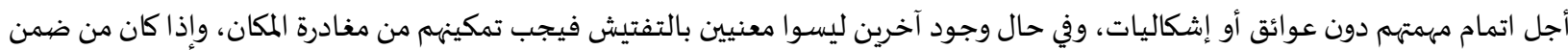
المشمولين بالتفتيش نساء فلا يقوم بتفتيشهم إلا النساء. إذا كان التفتيش بقصد ضبط المراسلات المكتوبة وما هو بحكمها يتعين على القائم بالتفتيش حال ضبطها أن لا يفتحها ولا يطلع عليها، وأن يقوم بتسليمها لجهة التحقيق التي أذنت بالتفتيش، كما يتعين عليهم أثناء قيامهم بالتفتيش المحافظة على سلامة المكان والممتلكات وما يحتويها من الأضرار أو التلف. توعية رجال الشرطة بأهمية التعامل بشكل حضاري وإنساني في حال اضطرارهم للقبض او التفتيش، وعدم التعرض لكرامة الناس، لأن من شأن ذلك أن يبني جسور للتواصل والتعاون ما بين أفراد المجتمع والأجهزة الأمنية. استخدام القوة وبالقدر اللازم إذا أبدى الطرف الثاني عدم تعاوناه أو أي مقاومة ولم يمتثل لأوأمر رجال الشرطة عند تنفيذ القبض أو التفتيش.

$$
\begin{aligned}
& \text { لمراجع: } \\
& \text { 1. حسن، سعيد عبداللطيف(د.ت). شرح قانون الإجراء/ت الجزائية الكويتي. مطبعة أكاديمية سعد العبدالله للعلوم الأمنية. } \\
& \text { 2. حومد،عبد الوهاب (1997). الوسيط في الإجراء/ت الجزائية الكويتية. مطبوعات جامعة الكويت. }
\end{aligned}
$$

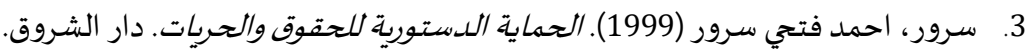

$$
\begin{aligned}
& \text { 4. سلامة، مأمون محمد (2008). الإجراءات الجنائية في التشريع المصري. دار النهضية العربية. }
\end{aligned}
$$

5. السماك، فاضل نصرالله وأحمد (2011). شرح قانون الإجراءات والمحاكمات الجزائية الكويتي. الطبعة الثانية. دار الهضية العربية للنشر والتوزيع.

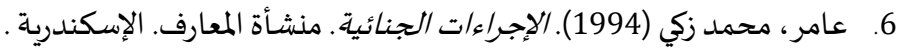
7. مهدي، عبد الرءوف (2013). شـح القواعد العامة للإجراء/ت الجنائية. دار النهضية العربية. القاهرة. 
www.refaad.com

$$
\text { المجلة الدولية للدراسات القانونية والفقهية المقارنة }
$$

International Journal of Legal and Comparative Jurisprudence Studies (LCJS)

Journal Homepage: https://www.refaad.com/views/LCJS/Home.aspx

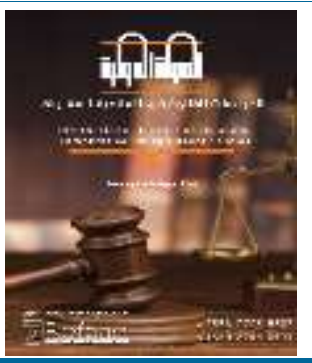

\section{Carrying out the inspection process as a criminal procedure while carrying out security works in accordance with the Kuwaiti legislations}

\section{Abdullah Ajlan Abdullah Aldousari}

Teaching staff member at the Police Courses Department, Saad Al-Abdullah Academy for Security Sciences, Kuwait boajlan2011@gmail.com

Received: 3/2/2021 Revised: 27/2/2021 Accepted: 23/4/2021 DoI: https://doi.org/10.31559/LCJS2021.2.1.4

Abstract: The Kuwaiti police is responsible for promoting safety and security. It is the main agency that is responsible for protecting people from internal threats. Under the law, it is responsible for protecting the state from criminals, crimes and the ones who violate the law and the public order.

While the police officers and the agencies cooperating with them carry out the criminal and administrative investigation, they may be forced to carry out the procedures of the inspection process in accordance with the rules stipulated in the penal law, the criminal procedures law and the relevant laws that complement the latter law.

Therefore, it was necessary to conduct the present researcher about this subject. The present study is divided into two parts. Each part is divided into two sections. The first part sheds a light on the conditions that must be met to consider the inspection process valid and the thing to be inspected. The second part sheds a light on the procedures, and characteristics of the inspection process. The goals sought from carrying out this study is represented in guiding the police officers and enlighten them about the way of carrying out the inspection process. That shall enable police officers to avoid any violation while carrying out the inspection process. However, if such a violation was committed, the procedures of the inspection process shall be considered invalid. The researcher reached several results and suggested several recommendations. In terms of the most significant result, it was found that the inspection process is an investigative procedure that violates the personal life, secrets and properties of individuals and families. Despite that, the Kuwaiti legislator permitted carrying out the inspection process due to certain conditions and considerations in order to promote public security and protect the society and its members from crime and criminals. In terms of the most significant recommendation, the researcher recommends promoting awareness among police officers about the way of dealing with people in a humane and civilized manner in case they had to arrest someone or carry out the inspection process. He recommends promoting awareness among police officers about the significance of refraining from infringing people's dignity. That shall contribute to improving the communication between the security agencies and the members of the society and promoting cooperation among them.

Keywords: inspection; Police force; General security; Dangers.

\section{References:}

1. 'amr, Mhmd Zky (1994). Alejra'at Aljna'yh. Mnshat Alm'arf. Aleskndryh.

2. Hsn, S'yd 'bdalltyf(D.T). Shrh Qanwn Alejra'at Aljza'yh Alkwyty. Mtb't Akadymyh S'd Al'bdallh Ll'lwm Alamnyh.

3. Hwmd,'bdalwhab (1997). Alwsyt Fy Alejra'at Aljza'yh Alkwytyh. Mtbw'at Jam't Alkwyt.

4. Mhdy, 'bdalr'wf (2013). Shrh Alqwa'd Al'amh Llejra'at Aljna'yh. Dar Alnhdh Al'rbyh. Alqahrh.

5. Slamh, Mamwn Mhmd (2008). Alejra'at Aljna'yh Fy Altshry' Almsry. Dar Alnhdh Al'rbyh.

6. Alsmak, Fadl Nsrallh Wahmd (2011). Shrh Qanwn Alejra'at Walmhakmat Aljza'eyh Alkwyty. Altb'h Althanyh. Dar Alnhdh Al'rbyh Llnshr Waltwzy'.

7. Srwr, Ahmd Fthy Srwr (1999). Alhmayh Aldstwryh Llhqwq Walhryat. Dar Alshrwq. 